\title{
Patients with high-dose diuretics should get ultrafiltration in the management of decompensated heart failure: a meta-analysis
}

\author{
Xiaofeng Shi ${ }^{1}$ Jiating Bao ${ }^{2} \cdot$ Haili Zhang ${ }^{3} \cdot$ Hao Wang ${ }^{1} \cdot$ Lei Li $^{4} \cdot$ Yue Zhang ${ }^{5}$
}

Published online: 17 June 2019

(C) The Author(s) 2019

\begin{abstract}
The identification of specific patients with decompensated heart failure (DHF) who may benefit from ultrafiltration (UF) is important in clinical practice. We undertook a meta-analysis to compare the effects of ultrafiltration and diuretics on major clinical outcomes. The outcomes included weight change, length of hospital stay, rehospitalization for HF, mortality, change in serum creatinine, dialysis dependence, and adverse outcomes. We identified 14 trials including 975 patients with HF, met the eligibility criteria. There was a reduction in heart failure-related rehospitalization in ultrafiltration group when compared with the diuretic group. Subgroup analyses revealed a trend toward the decreased HF readmissions in ultrafiltration plus diuretic therapy group but did not reach statistical significance compared with ultrafiltration alone therapy. Overall, UF treatment did not produce apparent beneficial effects for weight loss, lengths of hospitalization, total mortality, the change of serum creatinine, and dialysis rate. Subgroup analyses showed increase in the serum creatinine were significantly higher for a higher dose regimen (>200 mg/ day) when compared with lower dose diuretic therapy $(<200 \mathrm{mg} /$ day). As for adverse events, UF patients were associated with an increased risk of hypotension and lower risk of neurologic symptoms. The current results revealed ultrafiltration was associated with significant reduction in the rate of rehospitalization. Increase in the serum creatinine was observed in patients with high-dose diuretic regimen. Patients with high-dose diuretics should get ultrafiltration therapy.
\end{abstract}

Keywords Ultrafiltration $\cdot$ Diuretics $\cdot$ Decompensated heart failure $\cdot$ Serum creatinine $\cdot$ Meta-analysis

\section{Introduction}

Decompensated heart failure (DHF) has caused rising concerns of general public over these years. DHF is the common cause for hospitalization and emergency visit among medicare

Electronic supplementary material The online version of this article (https://doi.org/10.1007/s10741-019-09812-2) contains supplementary material, which is available to authorized users.

Lei Li

changhaibai@163.com

Yue Zhang

zhangyuetj@yeah.net

1 Emergency department, Tianjin First Center Hospital, Tianjin, China

2 Intensive Care Unit, Tianjin First Center Hospital, Tianjin, China

3 General Surgery Department, West China Hospital of Sichuan University, Chengdu, Sichuan, China

4 Department of Vascular Surgery, The Second Hospital of Dalian Medical University, Dalin, China

5 Institute of Urology, The second Hospital of Tianjin Medical University, Tianjin, China beneficiaries [1, 2]. Most HF patients went into emergency department with symptoms of volume of overload and abrupt onset of dyspnea. Traditional therapy of patients with DHF was diuretics which induced a rapid diuresis that reduced congestion and dyspnea [3, 4]. However, these drugs may cause acute kidney injury, abnormal neurohormonal activation, and electrolyte imbalance, and there is an urgent need to develop alternative treatment strategy that will favorably alter deadly condition.

Ultrafiltration as an alternative method is used to improve volume overload symptoms in all subsets of HF patients, including those with diuretic resistance or renal insufficiency [5-7]. The ability to precisely control the removal of sodium and water allows the ultrafiltrate extracted from serum during UF therapy to be isotonic. Many randomized, controlled trials (RCTs) have compared the efficacy and safety of ultrafiltration with pharmacologic therapy including UNLOAD (the Ultrafiltration versus Intravenous Diuretics for Patients Hospitalized for Acute Decompensated heart Failure) study [8], CARRESS-HF (Cardiorenal Rescue Study in Acute Decompensated Heart Failure) study [9], and AVOID-HF (Aquapheresis Versus Intravenous Diuretics and Hospitalization for Heart Failure) trial [10]. However, the 
results from the reported trials were inconsistent, leading to uncertainty about the effects of UF. The previously published systematic reviews that evaluated the efficacy of UF in treatment of patients with decompensated heart failure lacked appropriate safety evaluation or did not include all related trials $[11,12]$. There are still unanswered questions regarding whether ultrafiltration should combined with diuretic therapy, best types of ultrafiltration, the optimal rate of filtration, and the optimal dose of loop diuretics.

We therefore undertook a meta-analysis to compare the efficacy and safety of UF with diuretic therapy for decompensated heart failure patients.

\section{Methods}

\section{Data sources, search strategy, and selection criteria}

Relevant studies were identified by searching Medline via Ovid (from 1950 to December, 2018), Embase (from 1966 to December, 2018), and the Cochrane Library database (Cochrane Central Register of Controlled Trials), with relevant text words and medical subject headings that included "heart failure", "ultrafiltration", "clinical trial". Trials were limited to randomized controlled trials (RCTs) without language restriction. Reference lists from identified trials and review articles were searched manually to identify any other relevant studies. We also searched the Clinical Trials.gov website for relevant trials that were registered as completed but not yet published. We performed a systematic review of the published articles in terms of the approach recommended by the guidelines for the conduct of meta-analyses of intervention studies.

\section{Data extraction and quality assessment}

Published literatures were obtained from each eligible trial, and relevant information was extracted into a spreadsheet. The extracted data included patient age, serum creatinine, ejection fraction, inclusion criteria of patients, diuretics dose, and duration of ultrafiltration. The literature search, data extraction, and quality assessment (Grading of Recommendations Assessment, Development and Evaluation system) [13] were undertaken independently by two authors (Xiaofeng Shi and Jiating Bao) using a standardized approach. Any disagreement in extracted data was adjudicated by a third reviewer (Yue Zhang).

\section{Outcomes}

The outcomes included weight change, length of hospital stay, rehospitalization for HF, mortality, change in creatinine, dialysis dependence, and adverse outcomes.

\section{Statistical analysis}

The odd risk (OR) and 95\% confidence interval (CI) for each outcome were calculated before pooling by the random effects model. For the continuous variables, we used the weighted mean difference between groups. The percentage of variability across studies attributable to heterogeneity beyond chance was estimated with the $I^{2}$ statistic. Potential publication bias was assessed with the Egger test and represented graphically with Begg funnel plots of the natural log of the OR versus its standard error (SE). A two-sided $p$ value less than 0.05 was regarded as significant for all analyses. All statistical analyses were done with STATA (version 13.0) and Review Manager 5.0.

\section{Results}

\section{Trial flow and characteristics of included studies}

The literature search yielded 1047 articles, of which 21 were reviewed in full-text. A total of 14 trials including 975 patients with HF met the inclusion criteria in our study (Fig. 1) [8-10, 14-24]. The mean age ranged from 56 to 75 years and followup ranged from $12 \mathrm{~h}$ to 180 days. The UF group patients in four studies were randomized to UF combined with diuretics therapy, while in other seven trials, the UF group patients used UF therapy alone. The characteristics of the included studies are summarized in Table 1.

\section{Quality of trials}

Key indicators of trial quality were analyzed by modified Jadad quality scale system, including the process of randomization, concealment of allocation, and the use of intention-totreat analysis (Table 2).

\section{Weight loss}

Data regarding the effects of UF on weight loss were available from 12 trials including 991 participants. As shown in Fig. 2a, UF treatment did not produce an apparent beneficial effect for weight loss (weighted mean difference, $1.65 \mathrm{~kg}$ [95\% CI, 0.83 to $4.14 \mathrm{~kg}$ ], $\left.p=0.19 ; I^{2}=97 \%, p<0.001\right)$. Subgroup analyses were performed for the weight loss (Fig. 2b). No clear evidence of heterogeneity was found in comparisons of summary results obtained from subsets of studies grouped by ultrafiltration intervention, ultrafiltration flow rate, diuretics dose, patients' age, NYHA classification, and serum creatinine level (all $p>0.05$ ). 
Fig. 1 Identification process for eligible studies

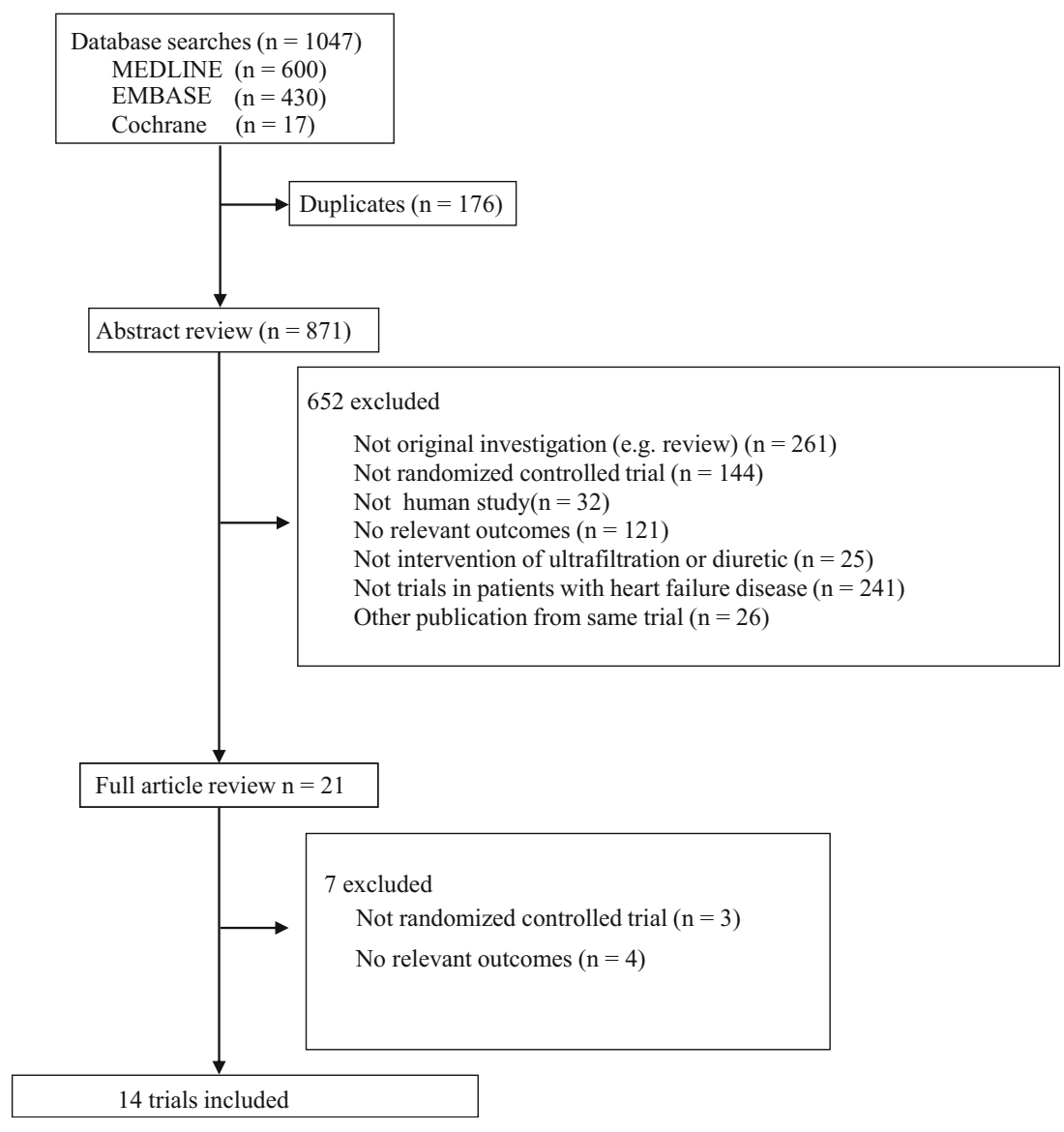

\section{Lengths of hospitalization and rehospitalization for $\mathrm{HF}$}

We next compare the efficacy of UF with diuretic therapy on lengths of hospitalization and rehospitalization for HF. Length of hospitalization was reported in 7 studies with 606 patients. There was no significant difference in lengths of hospitalization (weighted mean difference, -0.32 days [95\% CI, -1.34 to 0.69 days], $p=0.53 ; I^{2}=85 \%, p<0.001$, Fig. 3a) between this two groups. Subgroup analyses showed there were no clear evidence of heterogeneity in comparisons of summary results obtained from subsets of studies grouped by ultrafiltration intervention, ultrafiltration flow rate, diuretics dose, age, and NYHA classification (all $p>0.05$, Fig. $3 b$ ). In terms of rehospitalization, five studies reported 78 events in 341 patients with UF treatment (22.8\%) and 111 events of the 347 patients with diuretics therapy (31.9\%). There was a reduction in heart failure-related rehospitalization in ultrafiltration group when compared with the diuretic group (OR $0.64 ; 95 \% \mathrm{CI}$, 0.45 to $0.9, p=0.01 ; I^{2}=42 \%, p=0.14$, Fig. 4 a). We noted a different magnitude of effect according to the ultrafiltration intervention in trials; the OR was $0.70(95 \% \mathrm{CI}, 0.49$ to 1.00) for ultrafiltration plus diuretic therapy compared with 0.19 (95\% CI, 0.05 to 0.68 ) for ultrafiltration alone therapy ( $p$ for heterogeneity $=0.05$ ). There was no apparent heterogeneity of effect between trials grouped by ultrafiltration flow rate, diuretics dose, age, and serum creatinine (all $p>0.05$, Fig. 4b).

\section{Total mortality}

Eleven studies reported 65 deaths in 447 patients with UF treatment (14.5\%) and 63 deaths of the 460 patients with diuretics therapy (13.6\%). Overall, UF therapy did not reduce total mortality of HF patients $(1.05 ; 0.72$ to $1.53, p=0.79)$ as compared with diuretics therapy with no heterogeneity $\left(I^{2}=\right.$ $0.0 \% ; p=0.77$, Fig. 5 a). No clear evidence of heterogeneity was found in comparisons of summary results obtained from subsets of studies grouped by ultrafiltration intervention, ultrafiltration flow rate, diuretics dose, age, NYHA classification, and serum creatinine (all $p>0.05$, Fig. $5 \mathrm{~b}$ ).

\section{Changes of serum creatinine and dialysis dependence}

Eight trials including 606 participants reported the change of serum creatinine and eight studies reported 45 dialysis patients out of 811 total patients. There were no difference seen in the change of serum creatinine (weighted mean difference, $-0.01 \mathrm{mg} / \mathrm{dl}[95 \% \mathrm{CI},-0.18$ to $0.16 \mathrm{mg} / \mathrm{dl}$, $p=0.91 ; I^{2}=66 \%, p=0.005$, Fig. 6a) and dialysis rate 


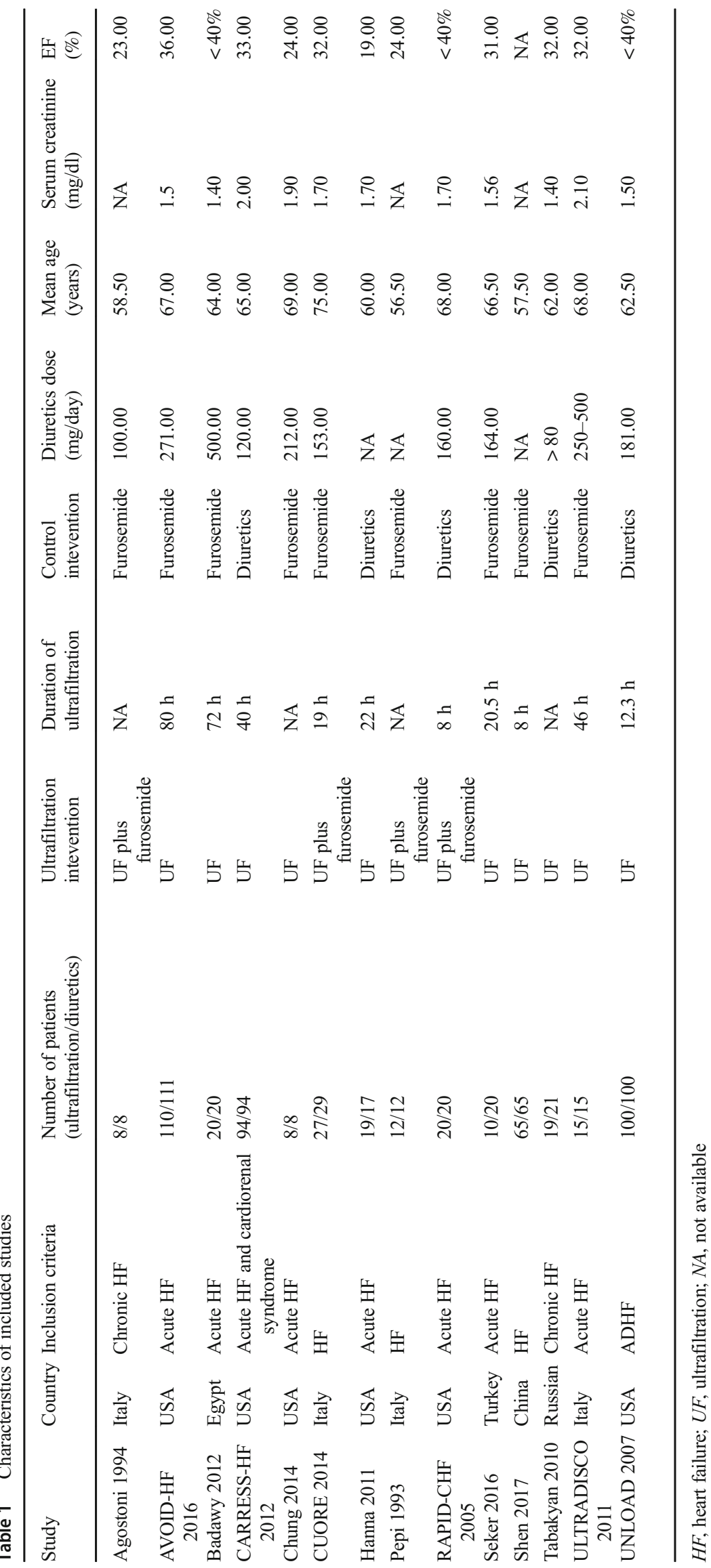


Table 2 Quality assessment

\begin{tabular}{|c|c|c|c|c|c|}
\hline Study & $\begin{array}{l}\text { Sequence } \\
\text { generation }\end{array}$ & $\begin{array}{l}\text { Allocation } \\
\text { concealment }\end{array}$ & Blinding & $\begin{array}{l}\text { Incomplete } \\
\text { outcome data }\end{array}$ & $\begin{array}{l}\text { Selective outcome } \\
\text { reporting }\end{array}$ \\
\hline Agostoni 1994 & Unclear & Unclear & No & Yes & No \\
\hline $\begin{array}{l}\text { AVOID-HF } \\
2016\end{array}$ & Yes & Unclear & No & Yes & No \\
\hline Badawy 2012 & Unclear & Unclear & No & Yes & No \\
\hline $\begin{array}{l}\text { CARRESS-HF } \\
2012\end{array}$ & Yes & Unclear & No & Yes & No \\
\hline Chung 2014 & Unclear & Unclear & No & No & No \\
\hline CUORE 2014 & Yes & Unclear & No & Yes & No \\
\hline Hanna 2011 & Unclear & Yes & No & Yes & No \\
\hline Pepi 1993 & Unclear & Unclear & No & Yes & No \\
\hline $\begin{array}{l}\text { RAPID-CHF } \\
2005\end{array}$ & Yes & Unclear & No & Yes & No \\
\hline Seker 2016 & Unclear & Unclear & No & No & No \\
\hline Shen 2017 & Unclear & Unclear & No & Yes & No \\
\hline Tabakyan 2010 & Unclear & Unclear & No & No & No \\
\hline $\begin{array}{l}\text { ULTRADISCO } \\
2011\end{array}$ & Yes & Unclear & No & No & No \\
\hline UNLOAD 2007 & Yes & Unclear & No & Yes & No \\
\hline
\end{tabular}

(1.49, 0.80 to $\left.2.79, p=0.21 ; I^{2}=0 \%, p=0.84\right)$ between the two groups (Fig. 7a). Subgroup analyses showed a different magnitude of effect according to the diuretic dose used in trials; the OR was -0.28 (95\% CI, -0.64 to 0.08 ) for a higher dose regimen (>200 mg/day) compared with 0.21 (95\% CI, 0.07 to 0.36$)$ for lower dose therapy $(<200 \mathrm{mg} /$ day) ( $p$ for heterogeneity $=0.01$, Fig. $6 b)$. Subgroup analysis for the effect of UF on dialysis was seen in Fig. 7b. No significant heterogeneity was found in these studies grouped by ultrafiltration intervention, ultrafiltration flow rate, diuretics dose, age, NYHA classification, and serum creatinine (all $p>0.05$, Fig. 7b).

\section{Adverse events}

Date on adverse outcomes were reported by a few trials, including worsening HF, cardiovascular outcome, hemorrhage, infection, hypotension, anemia or thrombocytopenia, electrolyte disorder, neurologic, filter clot, cerebral circulation disturbance, emergency department visits, and mechanical ventilation (Table 3 ). Six trials provided data for hypotension. UF patients were associated with an increased risk of hypotension $(2.39 ; 1.20$ to $4.76, p=0.01)$. Only two studies reported the events of neurologic symptoms and showed UF therapy was associated with a lower risk of neurologic symptoms $(0.35 ; 0.13$ to $0.93, p=$ 0.04 ), which limited the power of difference due to small sample size. There were no differences noted in the incidence of other adverse events between the two groups (all $p>0.05$, Table 3 ).

\section{Publication bias}

Begg's funnel plot and Egger's test suggested there was no evidence of publication bias for the outcome of rehospitalization ( $p=0.81$, Supplementary figure 1$)$.

\section{Discussion}

UF is a therapy full of promise, but has yet to find a definitive role. In this large quantitative systematic review comprising 14 trials and 975 individuals, we demonstrated UF therapy reduced HF-related hospital admissions compared with diuretic therapy. There was no evidence of any difference in weight loss, the length of hospitalization, and mortality rate. The changes of serum creatinine and dialysis rate were similar in both groups. Notably, increase in the serum creatinine was significantly higher for a higher dose regimen (>200 mg/ day) when compared with that of lower dose diuretic therapy ( $<200 \mathrm{mg}$ /day). There was an increased frequency of episodes of hypotension and a decreased frequency of neurologic symptoms in the UF group. These results suggested UF appears to be an efficacious therapy, but should be used with caution in HF patients.

ACCF/AHA guideline for the management of heart failure recommends ultrafiltration may be considered for patients with refractory congestion not responding to medical therapy $[25,26]$. The quality of the evidence was generally low $(2 \mathrm{C})$. The question of whether acute heart failure will benefit from ultrafiltration at an early stage remains unresolved. In recent years, many studies compared the effectiveness and safety of 


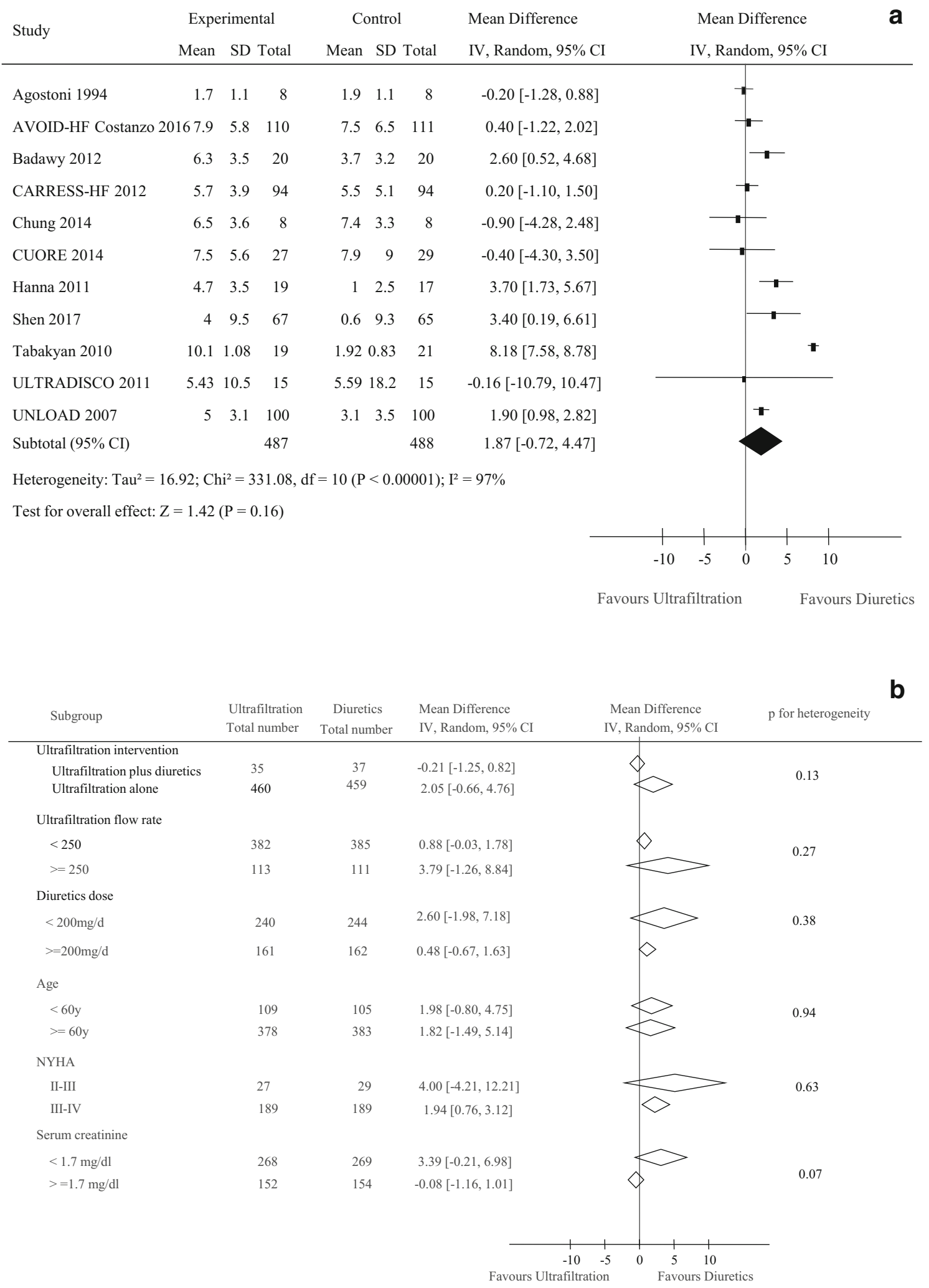

Fig. 2 Pooled weight loss (kg) (a) and subgroup analysis of weight loss (b)

diuretics versus ultrafiltration for the treatment of HF. The UNLOAD trial is the first landmark trial in this field [8]. The results showed ultrafiltration had a more pronounced effect on weight loss and fluid removal than diuretics therapy, and was associated with a decrease in rehospitalisation for 200 congested patients with AHF. One major shortcoming of this 


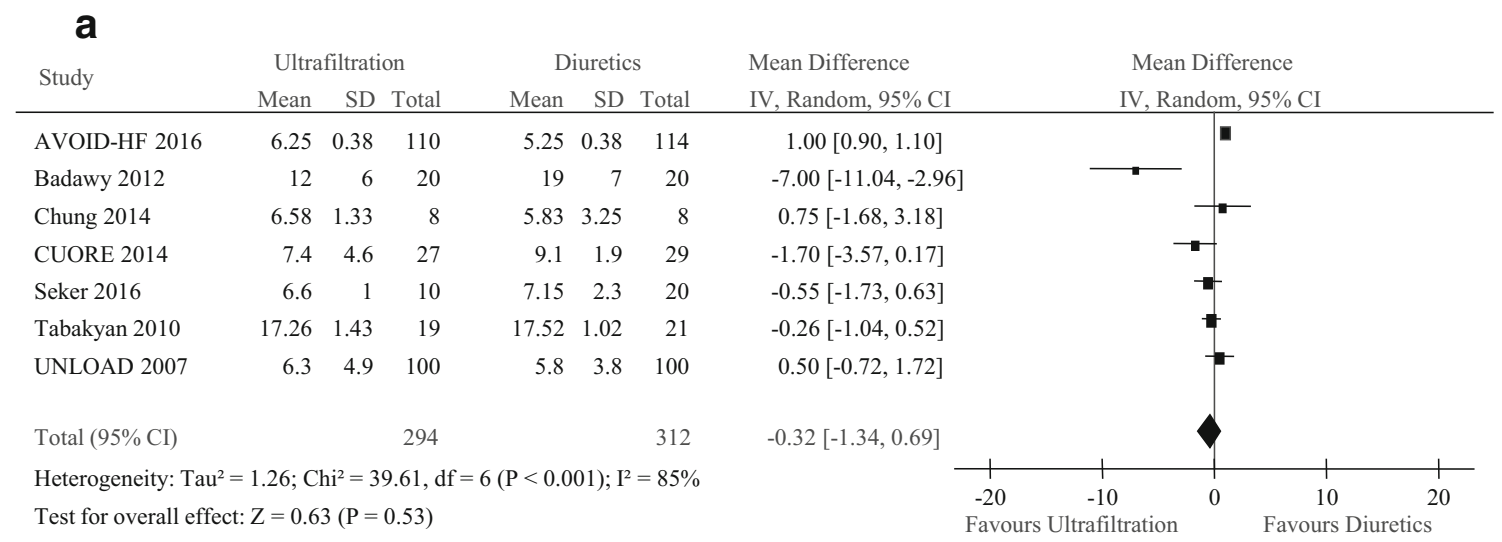

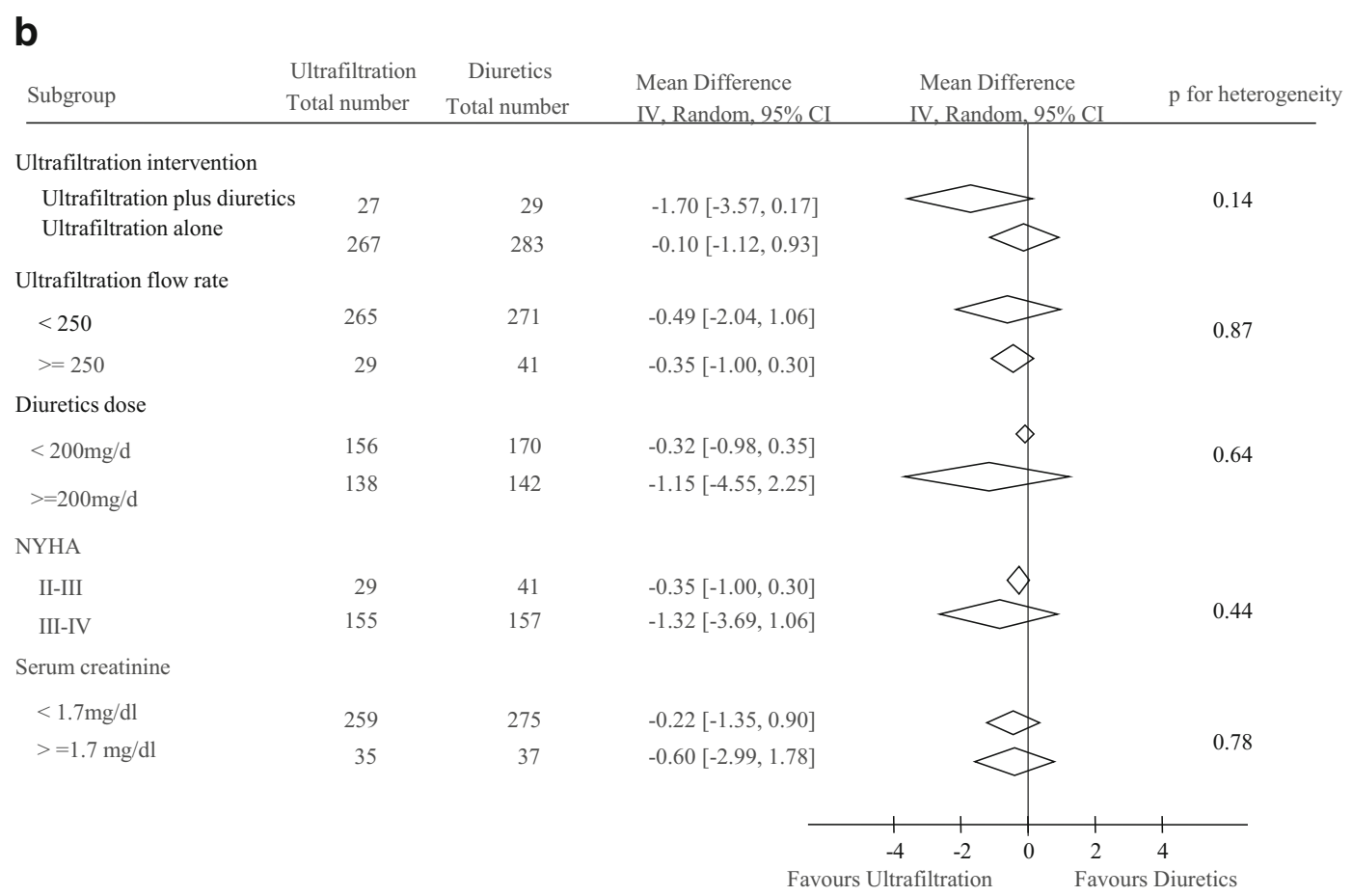

Fig. 3 Pooled lengths of hospitalization (day) (a) and subgroup analysis of lengths of hospitalization (b)

study was that the better outcomes in the UF group could be attributed to more complete decongestion. In a subsequent study, CARRESS-HF, conducted in 188 patients with AHF and worsening renal function, showed UF led to a worsening in renal function with no significant difference in weight reduction between the two groups [9]. Patients experienced more adverse events in the ultrafiltration group compared with diuretics group. The major shortcoming was that it had no measures in place to ensure optimal volume depletion in the UF group. The rate of fluid removal was mandated to be $200 \mathrm{ml} / \mathrm{h}$, which might be excessive for patients with hypotension and greater dependence on preload for hemodynamic stability. Recently, the AVOID-HF trial was terminated early when 224 of the 800 planned patients with AHF had been enrolled [10]. The preliminary data showed the UF group trended toward a longer time to first HF event within 90 days and fewer HF and cardiovascular events; also, more patients in the UF arm experienced adverse events. In AVOID-HF, the average UF rate of $138 \mathrm{ml} / \mathrm{h}$ was lower than $200 \mathrm{ml} / \mathrm{h}$ rate of the CARRESS-HF trial, and therapy was delivered over a longer period ( $70 \mathrm{~h}$ vs. $41 \mathrm{~h}$, respectively). However, similar to the UNLOAD trial, fluid removal was greater in the UF group, which would result in similar beneficial findings in AVOID-HF trial. Actually, in today's evidence-based world and pragmatic trials world, there was insufficient evidence to state one therapy over the other. A meta-analysis on ultrafiltration in acute heart failure by Waqas et al. demonstrated that ultrafiltration has advantages in fluid removal, weight loss, and reduction in heart failure rehospitalization [27]. Another review by Kwok et al. reported a consistent reduced rehospitalization effect of ultrafiltration compared with diuretics but no differences in weight loss, length of hospitalization, and 
a

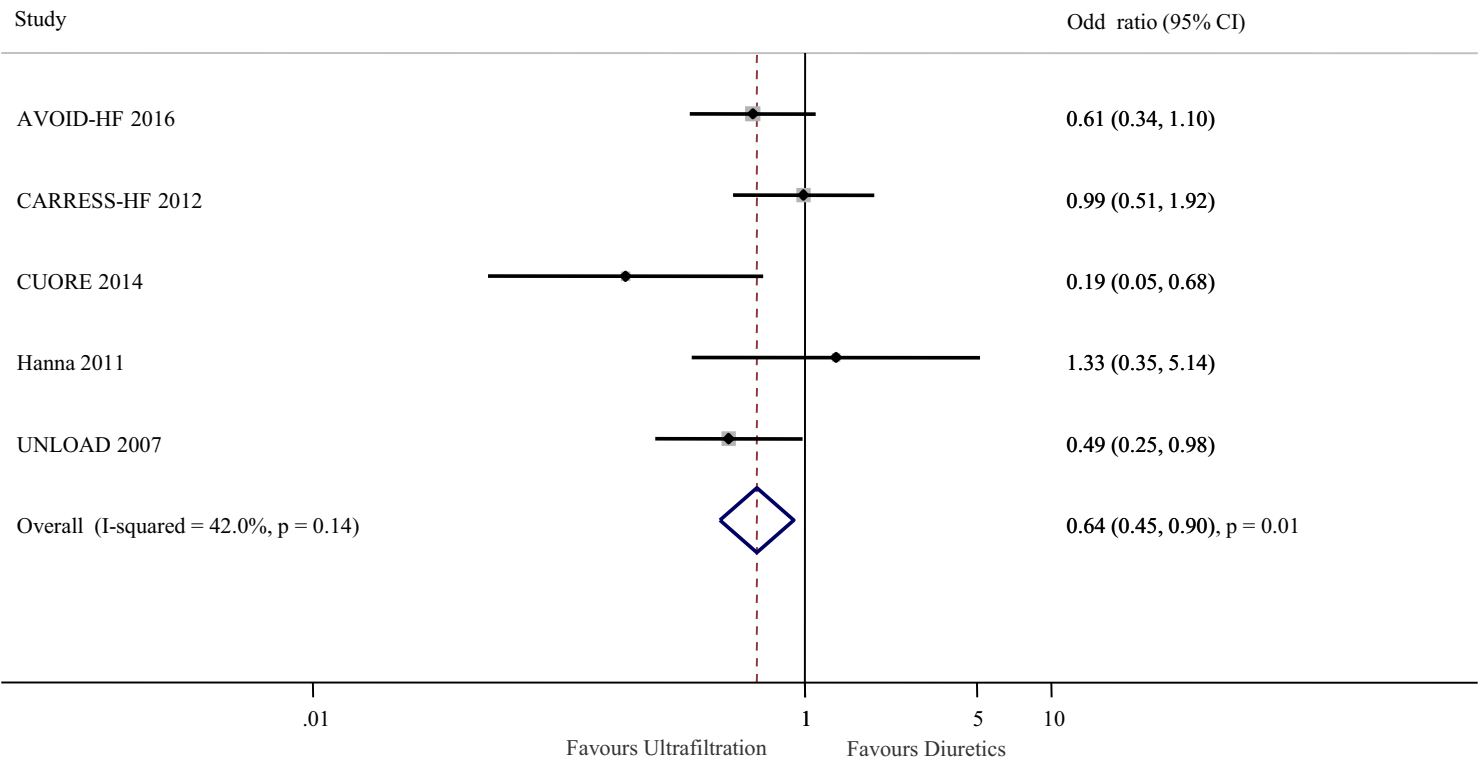

b

\begin{tabular}{|c|c|c|c|c|}
\hline Subgroup & $\begin{array}{l}\text { Ultrafiltration } \\
\text { Total number }\end{array}$ & $\begin{array}{c}\text { Diuretics } \\
\text { Total number }\end{array}$ & Odd ratio $(95 \% \mathrm{Cl})$ & $\mathrm{p}$ for heterogeneity \\
\hline \multicolumn{5}{|l|}{ Ultrafiltration intervention } \\
\hline Ultrafiltration plus diuretics & 27 & 29 & $0.70(0.49,1.00)$ & 005 \\
\hline Ultrafiltration alone & 314 & 318 & $0.19(0.05,0.68)$ & 0.03 \\
\hline \multicolumn{5}{|l|}{ Ultrafiltration flow rate } \\
\hline$<250$ & 322 & 330 & $0.60(0.42,0.86)$ & 0.2 \\
\hline$>=250$ & 19 & 17 & $1.33(0.35,5.14)$ & 7 \\
\hline \multicolumn{5}{|l|}{ Diuretics dose } \\
\hline$<200 \mathrm{mg} / \mathrm{d}$ & 217 & 222 & $0.60(0.38,0.94)$ & \\
\hline$>=200 \mathrm{mg} / \mathrm{d}$ & 105 & 108 & $0.61(0.34,1.10)$ & $\begin{array}{l}0.9 \\
7\end{array}$ \\
\hline \multicolumn{5}{|l|}{ Age } \\
\hline$<60 \mathrm{y}$ & 322 & 330 & $1.33(0.35,5.14)$ & 0.2 \\
\hline$>=60 \mathrm{y}$ & 19 & 17 & $0.60(0.42,0.86)$ & 7 \\
\hline \multicolumn{5}{|l|}{ Serum creatinine } \\
\hline$<1.7 \mathrm{mg} / \mathrm{dl}$ & 224 & 225 & $0.01(0.40,0.53)$ & 0.7 \\
\hline$>=1.7 \mathrm{mg} / \mathrm{dl}$ & 117 & 122 & $0.70(0.39,1.25)$ & 2 \\
\hline
\end{tabular}

Fig. 4 Pooled rehospitalization for heart failure (a) and subgroup analysis of rehospitalization for heart failure (b)

mortality [12]. Consistent with the results of Kwok et al., our analysis showed ultrafiltration treatment was associated with a reduction in the rate of rehospitalization for heart failure. Congestion is recognized as a major cause for rehospitalization in patients with DHF. It is conceivable that fluid removal could have a salutary impact on the rate of rehospitalization.
There was a trend toward the greater weight loss in ultrafiltration group in our analysis. Current study suggested that UF should be considered for management of patients with DHF; however, whether the high upfront cost of UF therapy would be offset by reduction in the rate of HF-related rehospitalization and resource utilization is yet unknown. This is an 
a

Study

Odd ratio $(95 \% \mathrm{CI})$

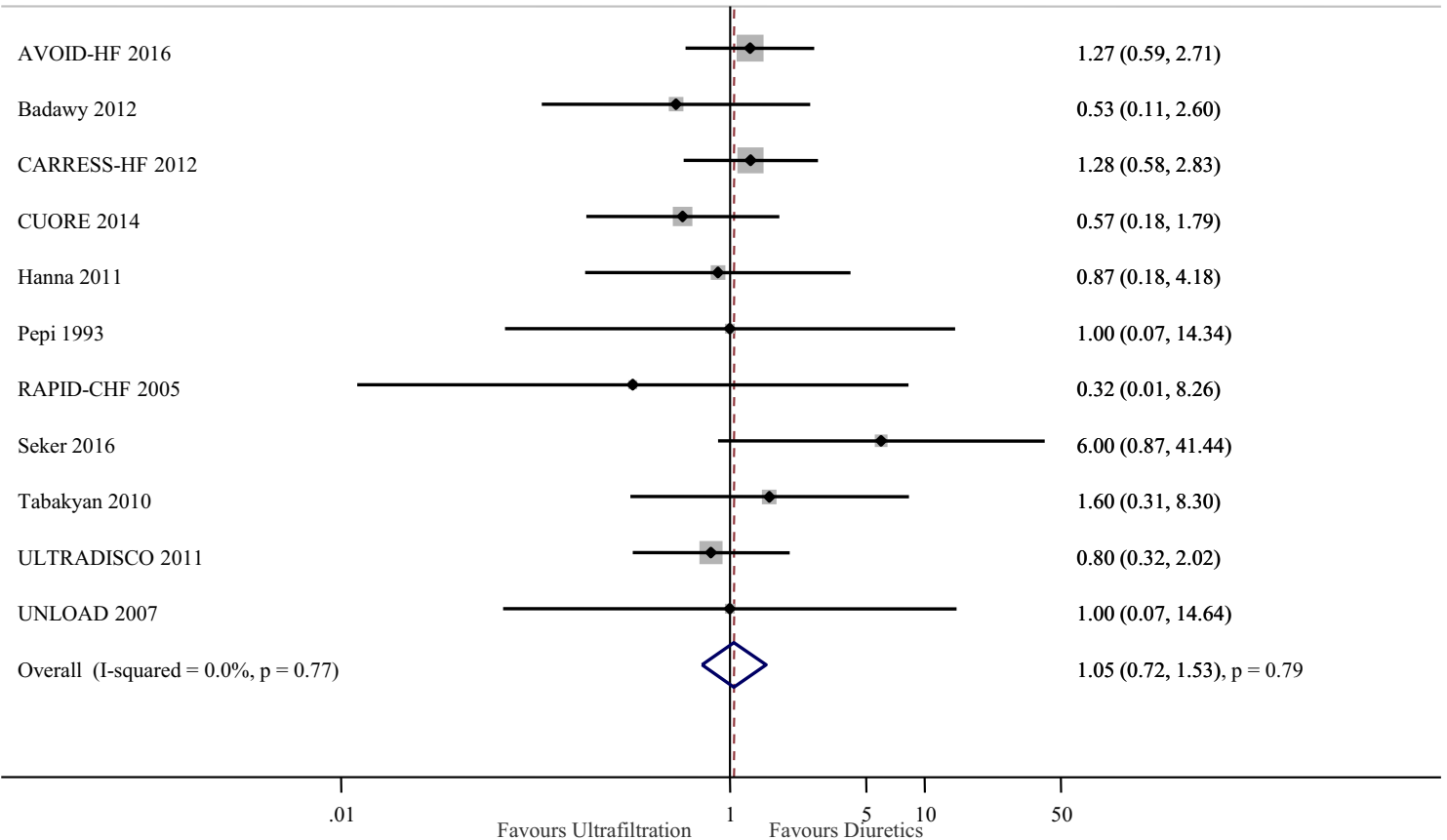

b

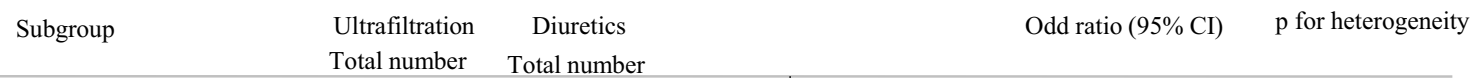

Ultrafiltration intevention

Ultrafiltration plus diuretics

59

Ultrafiltration alone

387

Ultrafiltration flow rate

$<250$

366

$>=250$

80

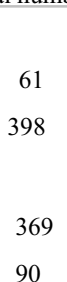

Diuretics dose

$<200 \mathrm{mg} / \mathrm{d}$

$>=200 \mathrm{mg} / \mathrm{d}$

270

145

Age

$<60 \mathrm{y}$

$>=60 \mathrm{y}$

46

400

44

415

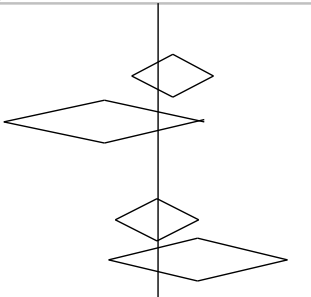

90

284

146

NYHA
II-III

III-IV

29

201

$<1.7 \mathrm{mg} / \mathrm{dl}$

$>=1.7 \mathrm{mg} / \mathrm{dl}$
Serum creatinine
298

136
309

138
$1.16(0.77,1.74)$

$0.59(0.22,1.59)$

$0.98(0.64,1.48)$

$1.46(0.60,3.55)$

$1.17(0.67,2.04)$

$0.97(0.56,1.68)$

$0.83(0.39,1.79)$

$1.13(0.73,1.75)$

$2.79(0.80,9.77)$

$0.69(0.39,1.23)$

0.05

$1.21(0.70,2.08)$

$0.92(0.54,1.57)$

0.64

0.49

0.48

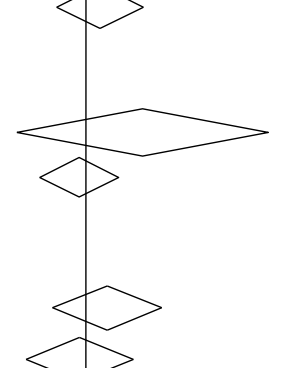

$0.92(0.54,1.57)$

Fig. 5 Pooled total mortality (a) and subgroup analysis of mortality (b) 


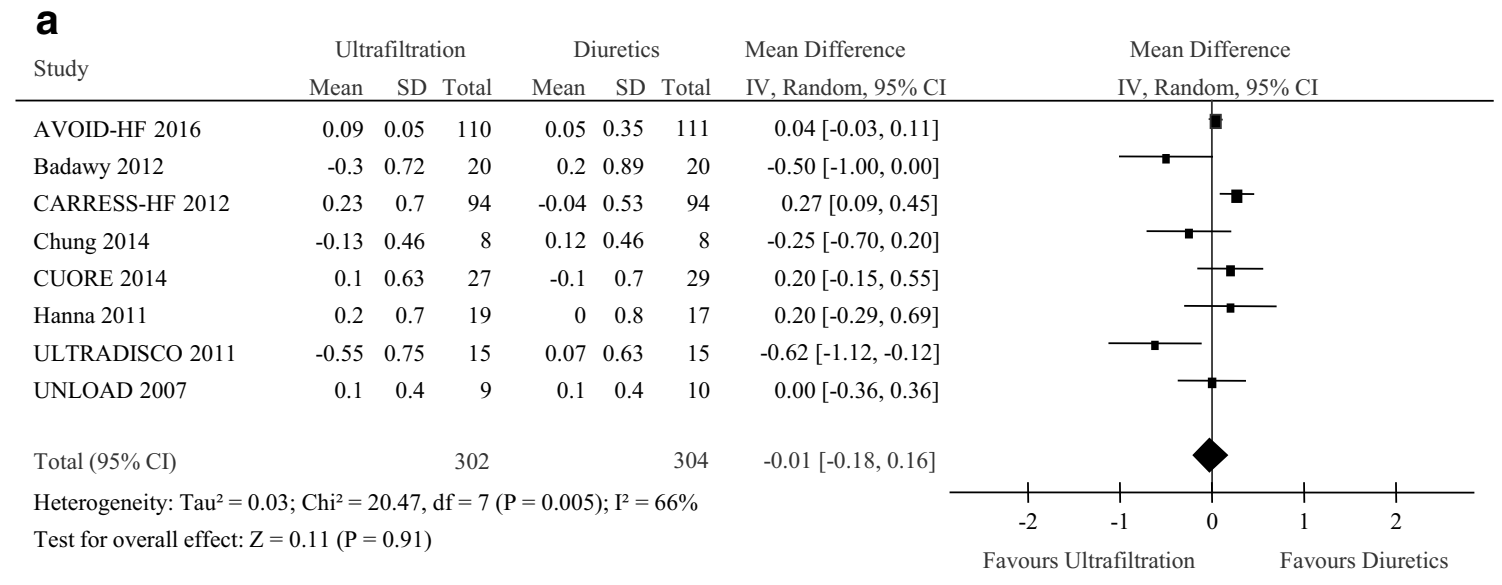

\section{b}

\begin{tabular}{|c|c|c|c|c|c|}
\hline Subgroup & $\begin{array}{l}\text { Ultrafiltration } \\
\text { Total number }\end{array}$ & $\begin{array}{c}\text { Diuretics } \\
\text { Total number }\end{array}$ & $\begin{array}{l}\text { Mean Difference } \\
\text { IV, Random, } 95 \% \text { CI }\end{array}$ & $\begin{array}{l}\text { Mean Difference } \\
\text { IV, Random, 95\% CI }\end{array}$ & $\mathrm{p}$ for heterogeneity \\
\hline \multicolumn{6}{|l|}{ Ultrafiltration intervention } \\
\hline Ultrafiltration plus diuretics & 27 & 29 & $0.20[-0.15,0.55]$ & & \multirow[b]{2}{*}{0.23} \\
\hline Ultrafiltration alone & 275 & 275 & $-0.05[-0.24,0.15]$ & & \\
\hline \multicolumn{6}{|l|}{ Ultrafiltration flow rate } \\
\hline$<250$ & 283 & 287 & $-0.03[-0.22,0.15]$ & & \multirow[t]{2}{*}{0.39} \\
\hline$>=250$ & 19 & 17 & $0.20[-0.29,0.69]$ & & \\
\hline \multicolumn{6}{|l|}{ Diuretics dose } \\
\hline$<200 \mathrm{mg} / \mathrm{d}$ & 130 & 133 & $0.21[0.07,0.36]$ & & \multirow{2}{*}{0.01} \\
\hline$>=200 \mathrm{mg} / \mathrm{d}$ & 153 & 154 & $-0.28[-0.64,0.08]$ & & \\
\hline \multicolumn{6}{|l|}{ Age } \\
\hline$<60 \mathrm{y}$ & 34 & 32 & $-0.21[-1.01,0.59]$ & & \multirow[b]{2}{*}{0.55} \\
\hline$>=60 \mathrm{y}$ & 268 & 272 & $0.04[-0.13,0.21]$ & & \\
\hline \multicolumn{6}{|l|}{ Serum creatinine } \\
\hline$<1.7 \mathrm{mg} / \mathrm{dl}$ & 158 & 158 & $-0.01[-0.20,0.18]$ & & \multirow[b]{2}{*}{0.86} \\
\hline \multirow[t]{3}{*}{$>=1.7 \mathrm{mg} / \mathrm{dl}$} & 144 & 146 & $-0.05[-0.43,0.32]$ & & \\
\hline & & & 1 & + & 1 \\
\hline & & & -2 & -1 & 2 \\
\hline
\end{tabular}

Fig. 6 Pooled the change in serum creatinine (mg/dl) (a) and subgroup analysis of the change in serum creatinine (b)

important point determining whether ultrafiltration should be routine used at early stage in HF while not as second-line treatment.

Although Kwok et al. published the most recent review, they did not analyze the adverse events. While intravenous diuretics were supposed to contribute to worsen renal function, no different effects on renal failure or creatinine changes between ultrafiltration and diuretics were observed in our study. Some other adverse effects were common in both groups, an increased frequency of hypotension was observed for ultrafiltration group and a higher risk of neurologic symptoms in diuretic arm. Other adverse events such as cardiovascular outcome, hemorrhage, or emergency department visits were not increased overall. Hypotension is commonly encountered in clinical practice. UF should be adjusted to suit the circumstances of each patient with lower blood pressure and greater dependence on preload for hemodynamic stability.

The challenge of our study was interpreting the findings in view of subgroup analysis. For a long period, diuretics have been used as the usual care of heart failure; however, the effectiveness often declined with repeated exposure of diuretics $[3,28]$. Use of ultrafiltration in HF has been shown to increase diuretic responsiveness. A question worth exploring is whether ultrafiltration plus diuretic therapy is superior to ultrafiltration alone. A trend toward the decreased HF readmissions in ultrafiltration plus diuretic therapy group was observed but did not reach statistical significance compared with ultrafiltration alone therapy. Diuretic agents were 


\section{a}

AVOID-HF 2016

Badawy 2012

CARRESS-HF 2012

CUORE 2014

Hanna 2011

Seker 2016

Tabakyan 2010

UNLOAD 2007

Overall (I-squared $=0.0 \%, \mathrm{p}=0.84)$
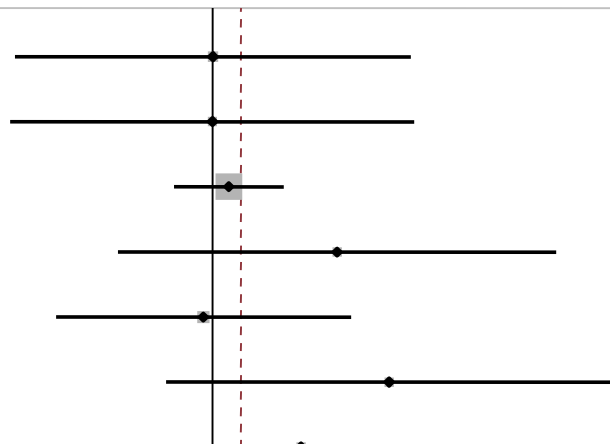

$1.26(0.58,2.73)$

$5.78(0.27,126.14)$

$0.88(0.11,7.06)$

$12.06(0.52,278.57)$

$3.49(0.13,90.86)$

$3.03(0.12,75.28)$

$1.49(0.80,2.79), \mathrm{p}=0.21$

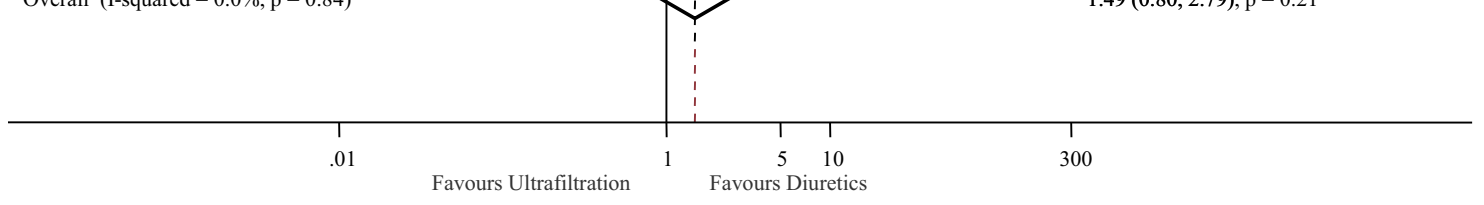

b

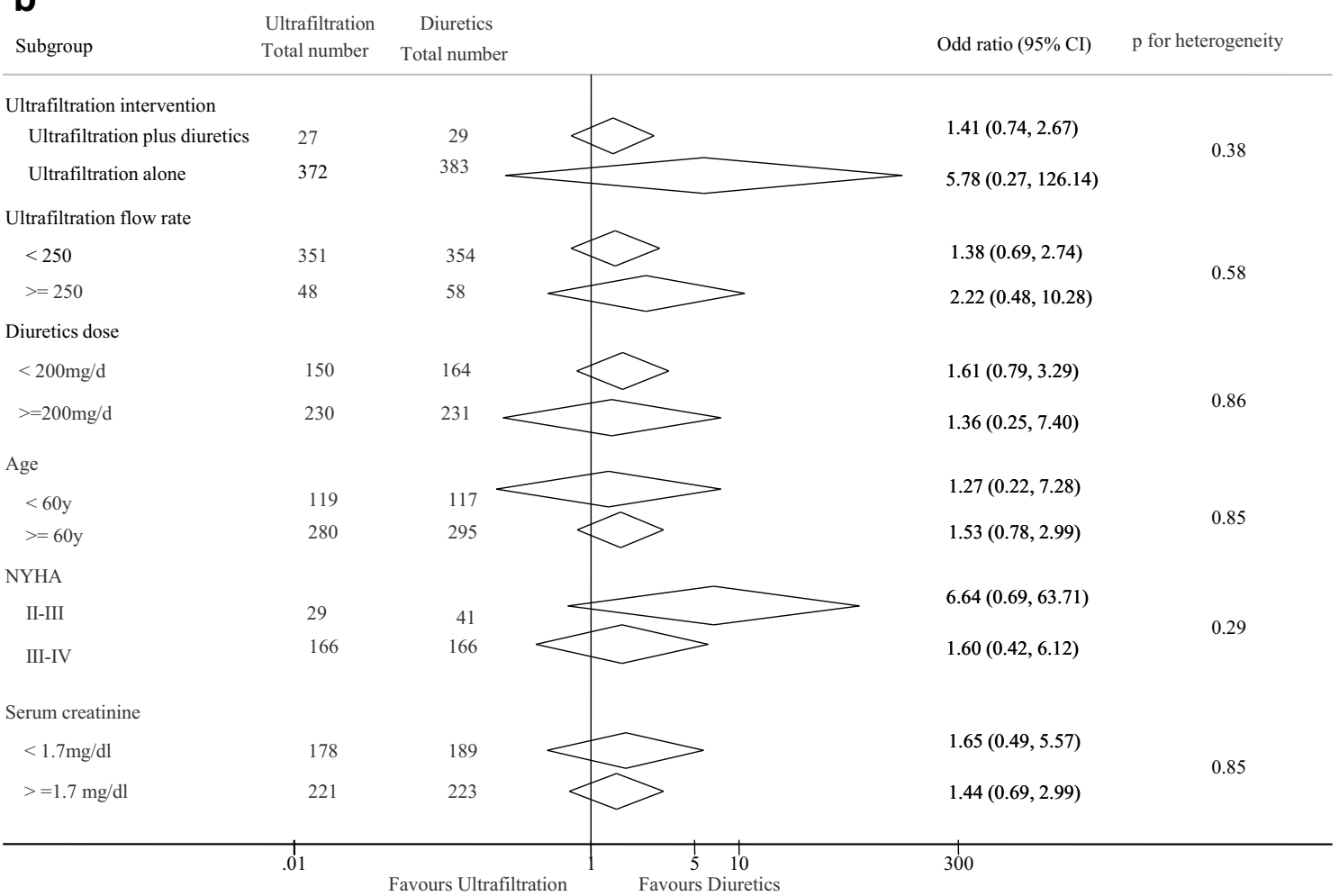

Fig. 7 Pooled dialysis dependence (a) and subgroup analysis of dialysis dependence (b)

stopped after randomization in many studies. Therefore, future studies should be designed to state whether ultrafiltration plus diuretic therapy is superior to ultrafiltration alone. Next, the efficacious and safe diuretic dose used in trials was needed to be determined. We found these was no significant difference between different doses diuretic (furosemide dose $>$ or $<$ $200 \mathrm{mg}$ /day) concerning weight loss and lengths of hospitalization, nor in rehospitalization for HF. As for safety endpoint, we noted increase in the serum creatinine was significantly higher for a higher dose regimen (>200 $\mathrm{mg} /$ day) when 
Table 3 Adverse events reported in the included RCTs

\begin{tabular}{|c|c|c|c|c|c|}
\hline Adverse event & Total trial & Events/ultrafiltration & Events/diuretics & OR $(95 \% \mathrm{CI})$ & $p$ value \\
\hline Worsening HF & 5 & $74 / 251$ & $101 / 249$ & $0.58(0.26,1.14)$ & 0.11 \\
\hline Cardiovascular outcome & 7 & $119 / 380$ & $139 / 381$ & $0.70(0.32,1.49)$ & 0.35 \\
\hline Hemorrhage & 5 & $15 / 333$ & $13 / 342$ & $1.19(0.30,4.76)$ & 0.80 \\
\hline Infection & 6 & $21 / 353$ & $15 / 366$ & $1.46(0.65,3.27)$ & 0.35 \\
\hline Hypotension & 6 & $28 / 271$ & $13 / 284$ & $2.39(1.20,4.76)$ & 0.01 \\
\hline Anemia or thrombocytopenia & 2 & $11 / 194$ & $5 / 194$ & $1.63(0.55,4.78)$ & 0.38 \\
\hline Electrolyte disorder & 1 & $0 / 94$ & $3 / 94$ & $0.14(0.00,2.72)$ & 0.19 \\
\hline Neurologic & 2 & $6 / 210$ & $16 / 211$ & $0.35(0.13,0.93)$ & 0.04 \\
\hline Filter clot & 2 & $7 / 127$ & $0 / 129$ & $8.35(1.00,69.24)$ & 0.05 \\
\hline Cerebral circulation disturbance & 1 & $1 / 19$ & $0 / 21$ & $3.49(0.13,90.86)$ & 0.45 \\
\hline Emergency department visits & 3 & $37 / 213$ & $43 / 211$ & $1.07(0.31,3.70)$ & 0.92 \\
\hline Mechanical ventilation & 1 & $1 / 20$ & $2 / 20$ & $0.50(0.05,5.08)$ & 0.56 \\
\hline
\end{tabular}

$R C T$, randomized controlled trials; $H F$, heart failure; $O R$, odd ratio

compared with lower dose diuretic therapy $(<200 \mathrm{mg} /$ day $)$. Worsening renal function has been associated with a strongly increased mortality in heart failure. Current practice guidelines suggested patients with a degree of diuretic resistance should get UF treatment. However, it was recently reported that worsening renal failure alone is not an independent determinant of the outcomes in patients with AHF [29]. Testani et al. recently showed no increase in urinary biomarkers indicative of tubular damage during diuretic therapy in the ROSE-AHF trial [29]. However, Akihiro et al. pointed out such patients who did not have an adverse outcome may have "pseudo-WRF" [30]. The prognosis might be different depending on the mechanism of renal dysfunction in HF. Therefore, interpretation of the impact of UF on the change of serum creatinine could prove challenging until we are able to better characterize renal function in the setting of HF. The clinical impact of diuretic dose in patients with ADHF was also explored. Peacock et al. analyzed data from the ADHERE registry including 82,540 patients with ADHF to compare the clinical and renal outcomes associated with lower versus higher loop diuretic dose $(<$ $160 \mathrm{mg}$ vs. $\geq 160 \mathrm{mg}$ of furosemide) [31]. The results showed patients receiving the higher doses of loop diuretic had a higher risk for in-hospital mortality, instances of worsening renal function, and prolonged hospitalization. Therefore, in this study, we support ultrafiltration as a bail-out therapy for patients with adequate diuretic therapy (>200 mg/day).

The study has some potential limitations. First, we found evidence of substantial heterogeneity in outcomes, although we tried to address this by using random effects model and subgroup analysis. We acknowledge the possibility that this heterogeneity had an impact on our results. Second, as the target populations of this meta-analysis were heart failure patients, the urgency of the disease and the seriousness of the consequences decided the moderate number and size of trials.
Last, there is lack of detailed diuretic protocol available in most trials.

\section{Conclusions}

The current results revealed ultrafiltration was associated with significant reduction in the rate of rehospitalization but not provided significant benefit on weight loss, length of hospitalization, and mortality. Increase in the serum creatinine was observed in patients with high-dose diuretic regimen. Physicians should take into consideration that patients with high-dose diuretics should get ultrafiltration therapy.

Acknowledgments We thank all authors whose publications could be included in our meta-analysis.

Authors' contributions Yue Zhang designed the study. Lei Li interpreted the results and revised the manuscript. Xiaofeng Shi, Haili Zhang, and Hao Wang collected the data. Xiaofeng Shi and Jiating Bao analyzed the results. Xiaofeng Shi drafted the manuscript.

\section{Compliance with ethical standards}

Competing interests The authors declare that they have no competing interests.

\section{Ethics approval and consent to participate Not applicable.}

Open Access This article is distributed under the terms of the Creative Commons Attribution 4.0 International License (http:// creativecommons.org/licenses/by/4.0/), which permits unrestricted use, distribution, and reproduction in any medium, provided you give appropriate credit to the original author(s) and the source, provide a link to the Creative Commons license, and indicate if changes were made. 


\section{References}

1. Fonarow GC, Adams KF Jr, Abraham WT et al (2005) Risk stratification for in-hospital mortality in acutely decompensated heart failure: classification and regression tree analysis. Jama 293:572580

2. Krumholz HM, Parent EM, Tu N, Vaccarino V, Wang Y, Radford MJ, Hennen J (1997) Readmission after hospitalization for congestive heart failure among Medicare beneficiaries. Arch Intern Med 157:99-104

3. Felker GM, Lee KL, Bull DA, Redfield MM, Stevenson LW, Goldsmith SR, LeWinter M, Deswal A, Rouleau JL, Ofili EO, Anstrom KJ, Hernandez AF, McNulty S, Velazquez EJ, Kfoury AG, Chen HH, Givertz MM, Semigran MJ, Bart BA, Mascette AM, Braunwald E, O'Connor CM, NHLBI Heart Failure Clinical Research Network (2011) Diuretic strategies in patients with acute decompensated heart failure. N Engl J Med 364:797-805

4. Yayla C, Akyel A, Canpolat U, Gayretli Yayla K, Eyiol A, Akboğa MK, Türkoğlu S, Tavil Y, Boyacı B, Çengel A (2015) Comparison of three diuretic treatment strategies for patients with acute decompensated heart failure. Herz 40:1115-1120

5. Andrade JG, Stadnick E, Virani SA (2010) The role of peripheral ultrafiltration in the management of acute decompensated heart failure. Blood Purif 29:177-182

6. Mielniczuk LM, Haddad H, Davies RA (2010) Ultrafiltration in the management of acute decompensated heart failure. Curr Opin Cardiol 25:155-160

7. Mittal MK, Katta N, Alpert MA (2016) Role of isolated ultrafiltration in the management of chronic refractory and acute decompensated heart failure. Hemodialysis International 20(Suppl 1):S30 SS9

8. Costanzo MR, Guglin ME, Saltzberg MT, Jessup ML, Bart BA, Teerlink JR, Jaski BE, Fang JC, Feller ED, Haas GJ, Anderson AS, Schollmeyer MP, Sobotka PA, UNLOAD Trial Investigators (2007) Ultrafiltration versus intravenous diuretics for patients hospitalized for acute decompensated heart failure. J Am Coll Cardiol 49:675-683

9. Bart BA, Goldsmith SR, Lee KL, Givertz MM, O'Connor CM, Bull DA, Redfield MM, Deswal A, Rouleau JL, LeWinter M, Ofili EO, Stevenson LW, Semigran MJ, Felker GM, Chen HH, Hernandez AF, Anstrom KJ, McNulty S, Velazquez EJ, Ibarra JC, Mascette AM, Braunwald E, Heart Failure Clinical Research Network (2012) Ultrafiltration in decompensated heart failure with cardiorenal syndrome. N Engl J Med 367:2296-2304

10. Costanzo MR, Negoianu D, Jaski BE, Bart BA, Heywood JT, Anand IS, Smelser JM, Kaneshige AM, Chomsky DB, Adler ED, Haas GJ, Watts JA, Nabut JL, Schollmeyer MP, Fonarow GC (2016) Aquapheresis versus intravenous diuretics and hospitalizations for heart failure. JACC Heart Fail 4:95-105

11. Chen HY, Chou KJ, Fang HC, Chen CL, Hsu CY, Huang WC, Huang CW, Huang CK, Lee PT (2015) Effect of ultrafiltration versus intravenous furosemide for decompensated heart failure in cardiorenal syndrome: a systematic review with meta-analysis of randomized controlled trials. Nephron 129:189-196

12. Kwok CS, Wong CW, Rushton CA, Ahmed F, Cunnington C, Davies SJ, Patwala A, Mamas MA, Satchithananda D (2017) Ultrafiltration for acute decompensated cardiac failure: a systematic review and meta-analysis. Int J Cardiol 228:122-128

13. Jadad AR, Moore RA, Carroll D, Jenkinson C, Reynolds DJM, Gavaghan DJ, McQuay HJ (1996) Assessing the quality of reports of randomized clinical trials: is blinding necessary? Control Clin Trials 17:1-12

14. Pepi M, Marenzi GC, Agostoni PG, Doria E, Barbier P, Muratori M, Celeste F, Guazzi MD (1993) Sustained cardiac diastolic changes elicited by ultrafiltration in patients with moderate congestive heart failure: pathophysiological correlates. Br Heart J 70:135-140

15. Agostoni P, Marenzi G, Lauri G, Perego G, Schianni M, Sganzerla P, Guazzi MD (1994) Sustained improvement in functional capacity after removal of body fluid with isolated ultrafiltration in chronic cardiac insufficiency: failure of furosemide to provide the same result. Am J Med 96:191-199

16. Tabak'ian EA, Zaruba A, Miasnikov RP et al (2010) Application of methods of renal replacement therapy for abolishment of hyperhydration in patients with decompensated chronic heart failure. Kardiologiia 50:30-35

17. Giglioli C, Landi D, Cecchi E, Chiostri M, Gensini GF, Valente S, Ciaccheri M, Castelli G, Romano SM (2011) Effects of ULTRAfiltration vs. DIureticS on clinical, biohumoral and haemodynamic variables in patients with deCOmpensated heart failure: the ULTRADISCO study. Eur J Heart Fail 13:337-346

18. Badawy SS, Fahmy A (2012) Efficacy and cardiovascular tolerability of continuous veno-venous hemodiafiltration in acute decompensated heart failure: a randomized comparative study. J Crit Care 27:106 e7-106 13

19. Hanna MA, Tang WH, Teo BW et al (2012) Extracorporeal ultrafiltration vs. conventional diuretic therapy in advanced decompensated heart failure. Congest Heart Fail 18:54-63

20. Chung ES, O'Brien TM, Menon S, Bartone C, Mazur W, Kereiakes DJ (2014) A pilot study of target weight guided treatment in acute heart failure using ultrafiltration or usual care: effect on sodium removal. Korean Circ J 44:156-161

21. Marenzi G, Muratori M, Cosentino ER et al (2014) Continuous ultrafiltration for congestive heart failure: the CUORE trial. J Card Fail 20:378 e1-378 e9

22. Shen XL, Zu LBY, Li L, Ma J, Zhang BJ, Jiang SB (2017) The efficacy and safety of ultrafiltration for patients with heart failure: results from a single-center randomized controlled study. Zhonghua Xin Xue Guan Bing Za Zhi 45:608-612

23. Li X, Liu Y, Lv J, Shi S, Liu L, Chen Y, Zhang H (2014) Progression of $\operatorname{IgA}$ nephropathy under current therapy regimen in a Chinese population. Clin J Am Soc Nephrol 9:484-489

24. Bart BA, Boyle A, Bank AJ et al (2005) Ultrafiltration versus usual care for hospitalized patients with heart failure: the Relief for Acutely Fluid-Overloaded Patients With Decompensated Congestive Heart Failure (RAPID-CHF) trial. J Am Coll Cardiol 46:2043-2046

25. Yancy CW, Jessup M, Bozkurt B, Butler J, Casey de Jr, Colvin MM, Drazner MH, Filippatos GS, Fonarow GC, Givertz MM, Hollenberg SM, Lindenfeld J, Masoudi FA, McBride P, Peterson PN, Stevenson LW, Westlake C (2017) 2017 ACC/ AHA/HFSA focused update of the 2013 ACCF/AHA guideline for the management of heart failure: a report of the American College of Cardiology/American Heart Association Task Force on Clinical Practice Guidelines and the Heart Failure Society of America. J Card Fail 23:628-651

26. Yancy CW, Jessup M, Bozkurt B, Butler J, Casey de Jr, Drazner MH, Fonarow GC, Geraci SA, Horwich T, Januzzi JL, Johnson MR, Kasper EK, Levy WC, Masoudi FA, McBride P, McMurray J, Mitchell JE, Peterson PN, Riegel B, Sam F, Stevenson LW, Tang WH, Tsai EJ, Wilkoff BL, American College of Cardiology Foundation, American Heart Association Task Force on Practice Guidelines (2013) 2013 ACCF/AHA guideline for the management of heart failure: a report of the American College of Cardiology Foundation/American Heart Association Task Force on Practice Guidelines. J Am Coll Cardiol 62:e147-e239

27. Siddiqui WJ, Kohut AR, Hasni SF, Goldman JM, Silverman B, Kelepouris E, Eisen HJ, Aggarwal S (2017) Readmission rate 
after ultrafiltration in acute decompensated heart failure: a systematic review and meta-analysis. Heart Fail Rev 22:685-698

28. Francis GS, Siegel RM, Goldsmith SR et al (1985) Acute vasoconstrictor response to intravenous furosemide in patients with chronic congestive heart failure. Activation of the neurohumoral axis. Ann Intern Med 103:1-6

29. Ahmad T, Jackson K, Rao VS, Tang WHW, Brisco-Bacik MA, Chen HH, Felker GM, Hernandez AF, O'Connor CM, Sabbisetti VS, Bonventre JV, Wilson FP, Coca SG, Testani JM (2018) Worsening renal function in patients with acute heart failure undergoing aggressive diuresis is not associated with tubular injury. Circulation 137:2016-2028
30. Shirakabe A, Hata N, Kobayashi N, Okazaki H, Matsushita M, Shibata Y, Uchiyama S, Sawatani T, Asai K, Shimizu W (2019) Worsening renal failure in patients with acute heart failure: the importance of cardiac biomarkers. ESC Heart Fail 6:416-427

31. Peacock WF, Costanzo MR, De Marco T et al (2009) Impact of intravenous loop diuretics on outcomes of patients hospitalized with acute decompensated heart failure: insights from the ADHERE registry. Cardiology 113:12-19

Publisher's note Springer Nature remains neutral with regard to jurisdictional claims in published maps and institutional affiliations. 